Portland State University

PDXScholar

2014

Forms and Functions : Life-Anatomy or Physiology?

Theresa Payne

Portland State University

Follow this and additional works at: https://pdxscholar.library.pdx.edu/honorstheses

Let us know how access to this document benefits you.

Recommended Citation

Payne, Theresa, "Forms and Functions : Life-Anatomy or Physiology?" (2014). University Honors Theses.

Paper 103.

https://doi.org/10.15760/honors.96

This Thesis is brought to you for free and open access. It has been accepted for inclusion in University Honors Theses by an authorized administrator of PDXScholar. Please contact us if we can make this document more accessible: pdxscholar@pdx.edu. 
Forms and Functions: Life-Anatomy or Physiology

by

Theresa Payne

An undergraduate honors thesis submitted in partial fulfillment of the requirements for the degree of

Bachelor of Science

in

University Honors

and

Philosophy

Thesis Adviser

Tom Seppalainen

Portland State University

2014

1| P a y n e 


\section{Forms and Functions: Life-Anatomy or Physiology?}

Explicit Definition: To maintain consistency and coherence of thought within this text all uses of the term "form" should be taken as; "Shape, arrangement of parts, visible aspect (esp. apart from colour)."1 This connotation of form is only to be understood as outward appearance or constitution of material entities. In no way is form to be taken in the Aristotelian, Platonic, or any philosophical sense; but as an aggregate of parts in functional relation to the environment. Any use of the term 'form' in quoted texts that does not reflect this usage will be changed by the author to essence, and will be annotated with an * and referenced in the footnotes.

\section{Introduction to the Distinction}

All forms of human centered communication are metaphors for experience. Humans use metaphors in an attempt to communicate internal concepts and connections of experience to others. Prelingual humans communicated past experience through the presence of physical markers which represented the experience of others. Before humans could speak, others' experience was represented metaphorically through paths worn by travel. A well-traveled path represented a desirable experience; water, food, shelter. Later in human history experience was metaphorized in pictograph form. Conveying experience imperative to existence like hunting grounds and practices. As human culture progressed so did systems of metaphors used to analogize experience and convey internal content others.

\footnotetext{
${ }^{1}$ (Fowler \& Fowler, p. 448)
} 
“Through analogies, the 'invisible becomes visible,' said Paracelsus². For the resemblances are neither useless nor unwarranted." ${ }^{3}$ To understand the world we are a part of, humans attempt to systematize metaphors used to convey conceptualizations of experience for a more coherent world view. The most structured system of metaphors is science. A problem with contemporary science is it seems to forget that theories used to explain phenomena of life and experience are inherently metaphoric. Theories are not actual representations of phenomena present to experience, they are an attempt to communicate abstracted experience and expected regularity. "We have become so used to the atomistic machine view; the world that originated with Descartes that we have forgotten that it is a metaphor. We no longer think as Descartes did that the world is like a clock. We think it is a clock."4 To better understand the experienced world, it is imperative to examine the cycles of thought that were contingent on preferred metaphoric description of the time they emerged. "In the study of living beings, history displays a pendulum movement, swinging to and fro between the continuous and the discontinuous, between structure and function, between the identity of phenomena and the diversity of beings." ${ }^{5}$

Webster and Goodwin assert; "A requirement for any experimental or theoretical work in a science is an adequate conceptualization of the object or the domain in which a phenomenon occurs." ${ }^{6}$ Terminology used to aid in conceptualization of scientific concepts has an effect in dictating understanding of a concept as well as epistemic tools and goals. "Modes of description and theoretical

\footnotetext{
${ }^{2}$ Paracelsus was a $16^{\text {th }}$ century physician known for founding the science of toxicology

${ }^{3}$ (Jacob, p. 21)

${ }^{4}$ (Lewontin, p. 14)

${ }^{5}$ (Jacob, p. 16)

${ }^{6}$ (Webster \& Goodwin, p. 15)
} 
explanation are conditioned by the ontological and epistemological theories which are available or fashionable and any conceptual system represents a historical choice from a number of possibilities."7 Historical choice of ontological and epistemic tools, can be correlated to dominant social, political, and cultural predilection of the time in which a concept emerged.

Evolution of meaning of organismic life, and metaphors used to describe it have been examined by philosophers of science such as Georges Canguilhem who, "Spotlighted the discontinuities in the conceptualization of life from antiquity to present, tracing life as animation, life as mechanism, life as organization, and finally, life as information." ${ }^{8}$ Metaphors used to describe organisms and their processes have gone through varying incarnations. Humans have a tendency to conceptualize complex phenomenon in language that is culturally relevant. Use of culturally relevant terminology can lend itself to greater conceptualization not only in the scientific community but in society as a whole.

What is relevant to society becomes not only the metaphor of scientific explanation but also provides the goal of science, inherent in the metaphor. Metaphors used to frame a scientific problem also outline expected knowledge that can be garnered through experimentation. An example being; description of genetic material being dubbed the genetic code, implicitly leads to a goal of deciphering the code. Scientific metaphors use culturally relevant terminology to outline goals of science that are pertinent to culture during that time.

\footnotetext{
${ }^{7}$ (Webster \& Goodwin, p. 15)

${ }^{8}$ Georges Canguilhem, "Epistemology of Biology," 1994; as cited in (Kay, p. 40) 
An ineffable experience, thus concept, is life. Life cannot be simply defined though descriptions and criteria to accurately represent phenomenon. It is of no surprise attempts to do so require some amount of abstraction. Depending on choice of abstraction; it leads to an overemphasis of one aspect of the phenomenon, while ignoring another. In the science of life two chosen emphases are mechanism and vitalism, nature and nurture, the list of dichotomies describing life and its process could continue. Theories concerning organismal development as presented in the vitalist view of Weismann and the mechanistic perspective of Wolpert, as discussed later, are theories that would appear to be contradictory but are both accepted biological generalizations, laws, within contemporary biology. With an analysis of underlying historical discontinuities in biology an understanding can be explicated of how the nature versus nurture dichotomy continues to be present in modern biology.

Susan Oyama has lead the call from developmental system theorists (DST) to eliminate dichotomous views in biology. DST is; "a general theoretical perspective on development, heredity and evolution. It is intended to facilitate the study of interactions between the many factors that influence development without reviving 'dichotomous' debates over nature or nurture, gene or environment, biology or culture." 9 Overall the scientific community is in agreement that life and development of organisms is interactional. Genetic interacts with environmental influences for organismal organization; but beating the dead horse of the nature versus nurture dichotomy continues, due to contemporary conceptual frame of 'biological information' and conceptual history of Western thought. Oyama states she;

\footnotetext{
${ }^{9}$ (Griffiths \& Gray, p. 417)
} 
"Would like nothing better than to stop beating him, ${ }^{10}$ but every time I think I am free of him he kicks me and does rude things to the intellectual and political environment. He seems to be a phantom horse with a thousand incarnations, and he gets more and more subtle each time around... What we need here, to switch metaphors in midstream, is the stake-in-the-heart move, and the heart is the notion that some influences are more equal than others, that essence*, or its modern agent, information, exists before the interactions in which it appears and must be transmitted to the organism either through genes or by the environment. This supports and requires just the conceptions of dual developmental processes that make up the nature-nurture complex. Compromises don't help because they don't alter this basic assumption"11

Science cannot stop beating the dead horse of the nature versus nurture dichotomy, because it is not dead it has been unknowingly resuscitated through attempts to extinguish it. Through a continued cycle of emphasis on mechanistic or vitalistic attributes of life, the nature versus nature dichotomy has thrived in different permutations depending on choice of popular science and intellectual traditions of the time. The trajectory of contemporary science is not that of narrowing epistemic practices to produce objective facts. The trajectory of science is a choice made through influence of what is relevant to society and the science is

\footnotetext{
${ }^{10}$ Stop beating the "dead horse"

*Original text states form in place of essence.

${ }^{11}$ (Oyama, pp. 26-27)
} 
emerging in. This has led to a hazy conceptualization of complex processes involved in ontogeny, reasserting a dichotomous view that the vitalistic aspects of life are somehow set apart from physical mechanistic actualization.

A science in desperate need of a conceptual, thus metaphoric, realignment is biology. Biology is the study of life. To illustrate need for a realignment of biology, two accepted descriptions of criteria of life will be examined. Then a historical perspective concerning intellectual climates that have continued the conceptual disconnect of organismal life will be analyzed. The two most recent illustrations of conceptual bifurcation of life; biological specificity and biological information will illustrate implications of this division. Lastly a structuralist account of biological life will be explicated in a hope that it will align with goals of developmental biology as outlined by proponents of the movement diverging from classical views of biological science, developmental systems theory.

\section{Defining Life}

The opening line of a college level introductory biology textbook states; "An organism is a life-form-a living entity made up of one or more cells. Although there is no simple definition of life that is endorsed by all biologists, most agree that organisms share a suite of five fundamental characteristics." ${ }^{12}$ The five characteristics outlined in this text are; energy, cells, information, replication, and evolution. Energy is the attribute of life to account for need to acquire and use energy from environmental sources; provided to photosynthesizing organisms through photosynthesis and its necessary component processes, non-photosynthesizing

\footnotetext{
${ }^{12}$ (Freeman, p. 1) *The following summary of the five characteristics are the author's; description in full on pages 1-2 of the text.
} 
organisms through cellular metabolization ${ }^{13}$ and its necessary components. Cells are units that constitute organisms or a colony,${ }^{14}$ that exhibit organization or order bound by semi-permeable membranes that permit passing of nutrients and energy to the inner constitution. Information is both transgenerational and environmental factors in which cellular organization occurs. Replication is a philosophically and scientifically fuzzy matter, this text uses an interesting metaphor stated by François Jacob to conceptualize the point; "The dream of a bacterium is to become two bacteria."15 Evolution is given an unsatisfactory tautologous description; "Organisms are the product of evolution, and their populations continue to evolve." ${ }^{16}$ With such a nonconcrete description of life, it is understandable not all biologist agree on a definition of object of their study, life.

The second description is also taken from a college level introductory biology text published a year earlier than the first. Considering that these texts are contemporary, aimed at the same audience, and have a goal of systemizing thought; a hope would be that their conceptual content concerning the most basic principle would correlate well. The second text does not acknowledge incomplete agreement of specialists in the field of biology concerning definition and description of life. The text introduces the subject of life boldly stating; "All living things share five basic properties passed down over millions of years from the first organisms to evolve on earth: Cellular organization, metabolism, homeostasis, growth and reproduction, and

\footnotetext{
${ }^{13}$ Metabolization-act of metabolizing; all the chemical reactions occurring in a living cell or organism

${ }^{14}$ Colony-An assemblage of individuals. May refer to an assemblage of semi-independent cells or to a breeding population of multicellular organisms. (Freeman, p. G:7)

${ }^{15}$ (Freeman, p. 2)

${ }^{16}$ (Freeman, p. 2) 
heredity." ${ }^{17}$ One aspect of life that can be agreed upon between these two texts ${ }^{18}$ is that there are five attributes of a living system. They do not use the same terminology, but possibly the terms correlate?

In text B cellular organization refers to organization of multicellular organisms or in a single celled organism. This feature of life correlates to text A's second criteria of life, cells. The important similarity of organization in these two descriptions of cells, is that of the semipermeable membrane. The important distinction between these attributes that illustrates discontinuities within biology is that A's definition requires "cells" not "cell" constitute life. While most unicellular organisms live as a group or colony; description A does not include a single celled organism as "alive" without assemblage of other individuals. By not allowing an individual single celled organism as possessing life, text A appears to be privileging the role of function over form. In the opening of text A it is granted that a single cell is an organism and a life form, the criteria requires multiple cells for function of life. In A's formulation a singular cell cannot function alone to constitute the form life; whereas text $B$ view a single celled organism as fulfilling the form of life and functions. While descriptions of cells juxtaposed with cellular organization seem to share important similarities when describing life; there is still a conceptual disconnect between formulations of life by experts in the field of biology.

Metabolism is the second criteria within text $\mathrm{B}$, and can be correlated to text A's first criteria of energy. There are no obvious discrepancies in conceptualization of

\footnotetext{
${ }^{17}$ Emphasis in original text (Johnson \& Losos, p. 3) The five attributes are summarized by the author; full description in text p. 3.

${ }^{18}$ For ease of comparison between texts the first text analyzed, Freeman, will be referred to text $A$ and the second, Johnson will be referred to as text $B$.
} 
this attribute, just an interesting distinction of conceptual priority. Energy is input and output of the mechanism of metabolism. Text A emphasizes vitalistic function, where text $B$ emphasizes form or mechanism supporting function. While seemingly similar metabolism and energy as a criteria for life, highlight different aspects of this phenomenon. This foreshadows later discussion concerning historical intellectual climates that have influenced contemporary science.

The third criteria of text B is homeostasis; "All living things maintain stable internal conditions so their complex processes can be better coordinated." ${ }^{19}$ This is an important element of life's processes that cannot be directly correlated to any criteria in text A. All cellular processes are regulated by what is analogized in science as negative feedback. ${ }^{20}$ The environment induces stress and change on an organismal system, and the system responds to maintain stable internal conditions, to continue life.

The fourth criteria of text B is growth and reproduction; "All things grow and reproduce." The fourth criteria of text A replication somewhat correlates with this principle. There are discrete and contested differences between the terms replication and reproduction that go beyond aim of this text. For this purpose it will be accepted that replication and reproduction carry a close enough conceptual resemblance. What is of import is text A's oversight of growth. A possible reason may be in line with text A's preference towards functions of life over forms in which it presents itself.

\footnotetext{
${ }^{19}$ (Johnson \& Losos, p. 2)

${ }^{20}$ Negative Feedback-A self-limiting, corrective response in which a deviation in some variable (e.g., body temperature, blood $\mathrm{PH}$, concentration of some compound) triggers responses aimed at returning the variable to normal. (Freeman, p. G:20)
} 
The fifth criteria of text $B$ is heredity. In this text heredity is discussed completely in terms of the genetic system, specifically the DNA molecule. This can be correlated to criteria four of A, information. While they are correlated; there is a distinct conceptual difference between information as posed in text A, and heredity in text B exclusively related to molecular DNA. Information in text A accounts for environmental and hereditary influences on life and development. Heredity in text B only accounts for molecular form, subjugating function of the molecule to its form.

Text B does not include evolution as a criteria for life, as text A does. Evolution is acknowledged previous to enumerating the properties shared by life. This could be because of assumptions behind evolution are difficult to analogize without falling into empty tautologous statements, as text A did. Another reason may be related to seemingly differing emphases between texts on either form or function of life. Evolution is a function of life, not a form of life.

An interesting note about text $A$, is what is introduced in the description but not in the criteria is evolution. It also does not mention homeostasis as criteria or within the initial description. This puts an overall presupposition on group or external dynamic of the life. What is mentioned in text B's introduction but not in the criteria, is the individual entity has autonomy of life within the system. The emphasis is on internal members of the system as representative of life. Overall text A appears to be concerned with what can be construed or distinguished as functions of forms of life, it places physiology over anatomy. Whereas text B emphasizes forms that convey the functions, physiology is subjugated to anatomy. Biology is in need of a conceptual realignment to agree on object of their inquiry; what is life? 
A second imperative question facing biology, is development of an organism. The question of development is of an individual organism, as well as development of species through evolutionary time for actualization of an individual. These two texts illustrate how descriptions and prioritization of form or function, as guiding principle, can translate into other conceptual difficulties. It can be agreed upon that development of an organism plays a role in life, but this role can be framed with an emphasis on either form or function.

Text A describes development as; "The entire series of events that occurs between the fertilization and maturity is called development. During development, cells become progressively more specialized or differentiated."21 These are functions of development, specialization and differentiation. There is no discussion of forms of anatomical components that actualize this function.

Text B describes development within an organismal system as; "An individual develops as cells divide, move, or expand in a directed way; begin to express certain genes rather than others; and signal to each other about where they are, what they are doing, and what type of cell they are becoming. In addition selected cells die in a regulated manner during development."22 This text emphasizes physical entities and relationship that constitute function of development. This description discusses a particular gene ${ }^{23}$ being expressed over another. Genes are loosely associated to physical structures within DNA. Also type of cell is accentuated in this description,

\footnotetext{
${ }^{21}$ (Johnson \& Losos, p. 449)

${ }^{22}$ (Freeman, p. 375)

${ }^{23}$ Gene- A section of DNA (or RNA, in some viruses) that encodes information for building one or more related polypeptides or functional RNA molecules along with the regulatory sequences required for its transcription.

(Freeman, p. G:12)
} 
placing primacy on anatomical forms that give actualization of function and development.

An explication of these two contemporary biological texts, illustrates the contemporary conceptual bifurcation of the object of study life and development. This shows how when systemized metaphors are attempted in science, there is a necessary abstraction of phenomenon for it to be represented. Abstraction of phenomenon puts an emphasis on either vitalistic functions of organisms and their physiology, or on mechanistic forms of organismal anatomy. To develop a more coherent conceptualization of the phenomenon of life it is necessary to analyze this bifurcation and historical climates that have reified, and thus lead to this distinction of form or function, anatomy or physiology as holding primacy in life.

\section{The Development of Life's History}

The problem that can be loosely described as that of nature versus nurture has persisted for millennia in Western thought. The seeming necessity to give a privileged role to either external or internal leads to the requirement of a central directing agency of development informing an organism either within organismic DNA or from the external environment directing organization from outside in. The requirement of a fruitful science is an adequate conceptualization of phenomenon attempting to be explained. To understand conceptual missteps within biology it is necessary to examine historical ideas that informed contemporary conceptualization of the object of biology, life.

The distinction between vitalism and mechanism, epigenesis and preformation, holism and atomism, nature and nurture can be traced as far back in Western thought 
as Democritus and Aristotle. "The Greeks laid one of the main foundations of Western culture. The first traces of vitalism and mechanism can already be found in their philosophy of nature. While Democritus proposed an atomistic theory, his opponent Aristotle formulated a holistic and teleological ${ }^{24}$ philosophy of nature. ${ }^{25}$ What these longstanding distinctions have in common is that they are in reference to life, thought, or knowledge but put an emphasis on either vitalistic internal self-directed organization system dictating function of an entity, or on mechanistic physical form in which function is processed. A popular metaphor in circulation currently is that of input and output in relation to a computer; mechanistic thought would explain all forms of the system composing function, vitalists would explain the system in terms of overall function guiding interaction of forms.

Biology has been influenced by two differing modes of theory, vitalism and mechanism, which have taken different incarnations over history, dependent on popular ideas of the time. When science is emphasizing the vitalistic aspects of life, the object of inquiry is the vitalizing force, the essential characteristic of life. In the vitalistic perspective, "A conception of a whole in which the parts have no autonomy or intrinsic properties, their nature following from that of the whole as the expression of some 'central' unifying or directing agency, usually conceived as being nonmaterial, an 'Idea' or 'soul.,"26

Aristotle was one of the first philosophers of Western thought that there is extant evidence of philosophy he espoused. His philosophy has been influential

\footnotetext{
${ }^{24}$ Teleology-The philosophical theory that all things in nature have a purpose and happen because of that. (Fowler \& Fowler, p. 938)

${ }^{25}$ (De Klerk, p. 3)

${ }^{26}$ (Webster \& Goodwin, p. 16)
} 
through history and continuing into contemporary times. "In the Middle Ages Aristotelian-Scholastic philosophy provided the unifying framework, which was marvelously suited to the description of living beings in terms of teleology and wholeness." ${ }^{27}$ Vital essence which is described in Aristotelian philosophy places an emphasis on function of life and its entities as a defining characteristic. Inchoate matter was informed by a vital force. Physical forms of organisms were of only secondary study to the function that they exhibited. The atomistic parts of organisms are present but the function that they display is object of study.

The view of development and organismal genesis in the Aristotelian view is epigenesis. "The epigenist assumed a vital force by virtue of which the organism obtained its different organs during a formative and teleologically directed process of growth." ${ }^{28}$ It was a directing force that was internal to the actualized organism that is responsible for epigenesis. The non-material guiding entity of an organism is responsible for presence and functions of life. It is through necessary functions of life for which physical manifestation of form actualizes itself.

The opposing emphasis of a mechanistic nature can be seen in the philosophy of Democritus as; "A conception positing atomic events together with the 'mechanical' interaction of autonomous units possessing certain intrinsic properties." 29 This view can be seen back to antiquity in the atomist philosophy of Democritus. It is physical three dimensional units interacting in nature, form, which defines functions within the physical world. This places an emphasis on external

\footnotetext{
${ }^{27}$ (De Klerk, p. 1)

${ }^{28}$ (De Klerk, p. 7)

${ }^{29}$ (Webster \& Goodwin, p. 16)
} 
qualities of parts of the system, prominence is on the external as a unifying directing force. It is the boundary in which parts interact that primacy lies in the mechanistic formulation of life.

The developmental and genesis of organisms in a preformationists view is; "A germ contains each part of the body in miniature; each part simply grows and nothing new appears." This formation of development and genesis presupposes an importance on a central directing agent that is external to the individual atomistic part. Physical components of organisms express life inherently. There is not an essence internal to the organism as a singular presence that allows for presentation of an individual, each component part has its own nature and amalgamation of parts that presents the function. As far back as ancient Greece bifurcation of form or function as representation of organismal life has been present, and re-presents its self in varying manifestations through history of Western thought.

An important indication of continued bifurcation of the conceptualization of life; can be seen in what Webster and Goodwin refer to as "German idealism" which is reflected in philosophy of Immanuel Kant, and "Protestant Natural Theology" as represented by the philosophy of David Hume. ${ }^{30}$ Both philosophies have had a great influence on Western thought. They each represent a continued tradition of placing primacy of life on either function or the form. Kant represents the vitalist. In his 'Critique of Judgment;' "Kant spells out in some detail the necessity of using teleological principles if biological organization is to be made intelligible." 31 There must be a function for the life form to be presented. Life cannot be present just

\footnotetext{
${ }^{30}$ (Webster \& Goodwin, p. 22)

31 (Webster \& Goodwin, p. 20)
} 
through chance, there must be a principle or function present for physical manifestation to occur. This shows that Kant carries on the conceptual bifurcation of life placing an emphasis on the vitalistic nature of life as the factor that dictates life.

On the other side of the fork is Natural Theology as represented by philosophical influence of David Hume. This incarnation of metaphoric description is aligned with mechanistic atomism of Democritus, emphasizing life conceptualized as; "Mechanical devices; that is as functional unities in which only structural relations are those of spatial contiguity." 32 There is no guiding purpose for formation of parts, through their formation of physical structures function is defined.

This conceptualization of life also subjugates cause and effect to constant conjunction of observed phenomenon. Hume's empiricist philosophy emphasized that only observable phenomenon could be object of scientific investigation. Cause never can be objectively discerned, all that is experienced is a "constant conjunction of events" that present an appearance of cause and effect. There is no cause for organismal life beyond contingent processes in which it presents itself. "The external functional relations of organisms considered in terms of the utility of the 'part' to the organism in relation to a particular mode of life in a particular environment. Internal functional relations, while by no means ignored, where relegated to a secondary status." 33 For Natural Theology the directing agency of life was externally guided through relation of physical parts, not a teleological function.

Conceptual misalignment in biology of form versus function, mechanism versus vitalism can also be seen in two widely accepted, groundbreaking, influential theories

\footnotetext{
${ }^{32}$ (Webster \& Goodwin, p. 22)

${ }^{33}$ (Webster \& Goodwin, p. 22)
} 
in biology; Darwinian evolution and Mendelian genetics. Darwin's theory of evolution is not based on observation of an individual or interaction of forms that produce a function. It is based on the function of evolution directing actualization of forms, which will provide apparatus for continued function. Darwin's theory of evolution caries on the vitalist tradition, placing function of phenomenon as object of study over the form. ${ }^{34}$

Mendelian genetics posed "unit factors," 35 as responsible for organismal development and life. Units present in parents are transferred through the act of fertilization to provide preexisting material forms that are actualized in organismal life. This formulation is directly correlated to ideas of preformation as seen in the mechanistic views of Democritus. Classic Mendelian theory represents one of many oscillations of thought from mechanism to vitalism, Mendelian genetics is a representation of the mechanistic.

Both Mendelian genetics and Darwinian evolution showed progress in understanding complex phenomena of life and development. The Darwinian view emphasized vitalistic functional processes as imperative for presentation of life. Evolution became the modern conception of epigenesis; the teleological guiding force presenting as the nonmaterial entity and function of evolution. Mendelian genetics is inherently preformationists, thus mechanistic. Mendelian genetics accentuated unchanging units passed from generation to generation, placing a privileged role on preexisting material entities responsible for life and development. Though these theories have played an imperative role in contemporary conceptualization of life,

\footnotetext{
${ }^{34}$ (Webster \& Goodwin, p. 23)

${ }^{35}$ (Moitra, p. 7)
} 
they also represent two underlying presuppositions in history of biological thought; primacy on either form and its mechanistic characteristics, or function and its vitalistic nature.

A final example of this conceptual bifurcation can be seen in germ ${ }^{36}$ theories of Weismann and Wolpert. With addition of microscope technology questions concerning the nature of organismal life moved from observation of macroscopic to that of microscopic phenomenon present at cellular level. Specifically physical entities in the nucleus of cells and their functions were given role of transmitting life.

Friedrich Weismann represents continuation of the vitalist epigenesis tradition. Weismann believed; "The problem of inheritance is not primarily to be thought of in terms of how the structure of the parent is to be transmitted to the offspring, rather it is to be considered in terms of control of growth and development." ${ }^{37}$ The highlighted aspect of this formulation of life and development is on function, control and growth; it subjugates importance of structure to function. Weismann believed in a structure within the germ cell that, "Has the power of developing into a complex organism." 38 He acknowledges structure but places it with a power beyond its structure.

Developmental biologist Lewis Wolpert also made investigations into germ cells as imperative for presentation of new life. Unlike Weismann's emphasis on controlling functions of cellular processes responsible for life, Wolpert emphasized spatial relations and order as presenting life. Wolpert proposed; "A co-ordinate

\footnotetext{
${ }^{36}$ Germ-a portion of an organism capable of developing into a new one (Fowler \& Fowler, p. 379)

${ }^{37}$ (Webster \& Goodwin, p. 27)

${ }^{38}$ (Webster \& Goodwin, p. 27)
} 
system which assigned a unique positional label to every point within it. The boundaries of the domain were defined by external values (maxima or minima) of the co-ordinate system, generated by a mechanism which was not specified but assumed." ${ }^{39}$ Director of this system was assumed as external to physical structure, through environmental influence, not a function inherent to a structure.

Both Weismann's and Wolpert's descriptions of germ cells as imperative to life and development are accepted in contemporary biology today, their theses being quite similar but show a distinct bifurcation in primacy of either mechanistic or vitalistic nature. Weismann's thesis can be summarized as; “Temporally or spatially organized variable in the external environment selected which particular set of determinants in the germ plasm would be expressed, and hence which of the possible alternative forms would be produced." 40 This formulation highlights a persistence of determinants in germ plasm that are triggered through environmental interaction to produce an organism. Form is selected through a function of interaction of environment and germ. Wolpert's thesis can be summarized as; "Spatially organized variable in the internal environment (positional information) determines which particular set of genes in each member of a (necessarily) spatially distributed set of genomes will be expressed and hence, ultimately, which component part of the total form will be realized in that part of space. ${ }^{41}$ Wolpert accentuates physical structure and location as object of investigation, showing a preference for mechanistic form over vitalistic function.

\footnotetext{
${ }^{39}$ (Webster \& Goodwin, p. 36)

${ }^{40}$ Emphasis present in original text (Webster \& Goodwin, p. 36)

${ }^{41}$ Emphasis present in original text (Webster \& Goodwin, p. 36)
} 
The way in which phenomenon is described places a primacy on either vitalistic or mechanistic attributes of life. The formulation of description provides the grid to which explanation is pinned. Metaphors used in a theory dictate observations which are deemed relevant. "In the dialogue between theory and experience, theory always has the first word. It determines the form of the question and thus sets limits to the answer." 42 Depending on theories espoused by popular science of the time, an emphasis is given to the mechanistic or vitalistic nature of life which outlines what phenomena can be object of investigation. The object of investigation dictates answers one is searching for.

\section{Informing Information}

Currently biological information is the chosen metaphor to describe phenomenon of life. The term information has been in common usage for centuries typically taken to mean; "Formation of mind and character, instruction and communicated knowledge." ${ }^{43}$ This term was not used with scientific precision, but as a term to denote ineffable experiences of personal and cultural development that are imperative to human. Information is a somewhat empty metaphor, a catachresis, a signifier without a referent. If metaphors attempt to communicate internal states and expected regularity, any communication verbal or nonverbal could be construed as information. Even further, chemical signals such as pheromones ${ }^{44}$ that are not directly perceptible to experience could be deemed information. Anything internal or external to the system that stimulates perception and experience could be information.

\footnotetext{
42 (Jacob, p. 15)

${ }^{43}$ (Kay, p. 77)

${ }^{44}$ Pheromone-a chemical substance produced by an organism in order to attract others of the same species, especially for reproductive purposes (Freeman, p. G:22)
} 
In the late 1940's two mathematicians Warren Weaver and Claude Shannon both introduced their theory of communication and information into discourse of science. This discipline was designed to formulate more efficient telephone systems, with the goal of transferring "information" through telephone wires. ${ }^{45}$ Warren Weaver introduced the term information into his theory with a definition differing from commonsense usage of the term. Information was; "The capacity of a system to transmit any sequence of symbols depended solely on distinguishing at the receiving end between the results of various selections made at the sending end-not on the meanings of these sequences." ${ }^{46}$ This means that for any system with an input and an output, where it can be discerned by output that there has been changes in input of the system. Weaver is quoted as saying, "The word 'information' in this theory [mathematical theory of communication] is used in a special sense that must not be confused with its ordinary usage. In particular, information must not be confused with meaning." ${ }^{27}$ Information is a functional relationship that is not dependent on the medium which it is produced.

Another application of the metaphor information to describe complex dynamic systems came about in the late 1940s from Norbert Wiener in cybernetics, a formalized notion of feedback. "Wiener transformed Schrödinger's statistical mechanical arguments into an information discourse encompassing all self-regulating systems." 48 Weiner believed that information could be calculated as negative entropy. Information being the metaphor for organismal organization. Weaver and Shannon on

\footnotetext{
${ }^{45}$ (Sterelny \& Griffiths, p. 101)

${ }^{46}$ (Kay, p. 95)

${ }^{47}$ (Kay, p. 14)

${ }^{48}$ (Kay, p. 85)
} 
the other hand argued that information within a system could be calculated as entropy. If one could discern disorder of a system then organization would be the inverse. Weiner argued; "Just as the amount of information in a system is a measure of its degree of organization, so the entropy of a system is a measure of its degree of disorganization; and one is simply the negative of the other." 49 There seemed to be no difficulty with this for either mathematician or use within biology, it was seen as somewhat a mathematical pun. ${ }^{50}$

Because of the theoretical definition of information within the mathematical theory of communication and cybernetics, it seemed unproblematic to add it to the concepts of biology. Information carried by organisms could be discerned by regularity of offspring's appearance being similar to the parent. In the Late 1950s mechanisms of phage replication as described by Delbrück and Gunther Stent, believed as many molecular biologist did "it would be unwise not (to) [sic] give some currency to 'information transfer' as a possible replication mechanism." ${ }^{51}$ This consideration heralded shift again to an emphasis on vitalistic characteristics of life.

Biology has traditionally not been seen as an exact science such as physics or chemistry. It was only in decades after World War II that information became for the first time a "physical parameter and a precisely defined concept" 52 Information as relating to discourse of biology emerged in an attempt to unify biology with sciences that showed a greater ability to make systematic and quantifiable theories, thus predictions. What is important to recognize about this choice of appropriation of

\footnotetext{
${ }^{49}$ Norbert Weiner, Cybernetics; 1961, p. 11 as cited in (Kay, p. 85)

${ }^{50}$ (Kay, p. 94)

${ }^{51}$ (Kay, p. 39)

${ }^{52}$ (Kay, p. 77)
} 
metaphor, is that information places an emphasis on internal vitalistic function of the system, as opposed to mechanical form of the system that actualizes function.

The positive of this nonconcrete metaphor, is that it leant toward the goal of a unified science. Formulas derived from the mathematic theory of communication could be applied to model other systems. Formulas of the mathematic theory of communication greatly improved computer modeling and cybernetics. It would not be far for biology to reach out to this new discipline in an attempt to describe interactions within complex biological systems. Members of biological sciences who originally embraced this term understood its metaphoric value, and did not intend reinstantiating the idea of a vitalistic force in contemporary biology.

What can be extrapolated from use of information within scientific lexicon is that information is the function of organisms and their interactions. It does not place any emphasis on content or physical form that carries information, only order of a system. Biological discourse framed on information shows the continued pendulum of scientific investigation swinging towards vitalistic description of life and its processes.

Power of the biological system became metaphorized as a nonconcrete entity providing order, an unseen directing power on the physical form.

\section{The Space of Specificity}

Previous to addition of biological information to the scientific lexicon biological phenomena was described using the metaphor of specificity. Biological specificity is related to corresponding or complementary spatial configurations between biological 
systems. ${ }^{53}$ Specificity was conceptually grounded through the traditional lock and key model where a key/organism is constructed to fit a lock/environment. The lock and key model of specificity is a simplification, as any abstraction of phenomena. What is lacking in the traditional lock and key model is dynamic vitalistic interaction between systems or parts of systems that relate to produce complex biological phenomena inherent in specificity as defined by developmental biologist Paul Weiss.

Paul Weiss gave an in depth description of phenomena that can be tied conceptually to the term specificity, and attempted to tie terminology and phenomena in biology to known phenomena in the realm of physical and chemical science. "We must treat cells as physical systems in space and time, endowed with definable properties which are subject to the limitations of all physical bodies and their laws of behavior." 54 Weiss' object of study was the cellular level, but his description of specificity based on "molecular ecology"55 can be extended to larger systems. This elegant ten point description of interactions within biological systems can be conceptually correlated to the dynamic interaction that is biological specificity in the development of organisms and their environment.

"The concept formulated in these ten points takes into account the growing realization that the structural and working order of the cell is based not on the presence of a fixed mechanical framework pervading it abundantly disproved by the facts but on a regular distribution in space of the various intracellular processes: a dynamic rather than static

\footnotetext{
${ }^{53}$ (Weiss, p. 256)

${ }^{54}$ (Weiss, p. 239)

${ }^{55}$ Molecular ecology is an attempt to interpret cellular affinities in terms of molecular structure and organization. (Weiss, p. 252)
} 
skeleton, maintained by metabolic energy and determined in its characteristics by some definite geometrical order in the field of its operation." 56

The ten points are summarized, including mechanistic implications as follows; ${ }^{57}$

1. Each system is made of numerous types of species of different composition, size, densities, rank and stability. Some segments of a system occur in relatively constant symbiotic groupings. Species are described completely by their physical and chemical composition. Some species interact in a relatively constant manner due to their physical and chemical constitution being complementary. This description of interaction is completely mechanistic, atomic parts interact within the environment and because of this interaction of parts, function emerges.

2. One of the fundamental characteristics of a system is that various species of the system are not self-sufficient, but are dependent in various degrees on other members of the population, as well as physical conditions within space they occupy. Survival and function of the system is predicated on presence of all necessary species. A system cannot consist of only a single species. It is necessary for survival of the system for species to interact within physical space. From the presence of physical species dependent upon each other a function emerges from interaction of parts. A mechanism must have a variety of cogs and wheels for a function to arise.

3. Interactions between species only occur within a limited range of conditions specific for its kind. These conditions are "existential and operational prerequisites" 58

\footnotetext{
${ }^{56}$ (Weiss, p. 255)

${ }^{57}$ Ten points summarized by author, substituting the term system for cell, complete description in endnotes (Weiss, pp. 252-255)

${ }^{58}$ (Weiss, p. 253)
} 
for each species or group. Existential and operational prerequisites of a species, refers to spatial configuration of a given environment ${ }^{59}$ as well as chemical composition of the environment. A species cannot exist in a system without already existent chemical configuration and gradation. DNA only maintains its structure in specific conditions with an addition of heat or chemicals it becomes denatured. This is what is meant by existential and operational prerequisites; already present chemical and physical conditions which attract a diversity of species necessary for the system's operation. The use of existential and operational prerequisites, is a purely mechanistic description.

4. If specific existential and operational prerequisites for various species differ at different sites within the system, species will automatically segregate into their appropriate environment. Due to environmental affinity an indiscriminate mixture of species can be sorted into a definite spatial pattern. Due to already existent conditions of the environment in which a system is instantiated, species will segregate appropriately to their preferences. Cogs and other parts of a clock automatically segregate depending on fit and preference of interaction. The mechanism self organizes, the emphasis is on the parts.

5. The fifth criteria clearly summarizes earlier criteria giving more description to interactions of species from the micro order to the macro, and cannot be summarized with justice.

"While the conditions and forces which determine the molecular regrouping are of the most diverse sorts; electric charges, surface

\footnotetext{
${ }^{59}$ Environment in this context is any physical, chemical, spatial or temporal contingency within the system.
} 
tensions, coacervation ${ }^{60}$, solubility, chemical affinities, adsorption, enzyme-substrate relations, mobility, elasticity, etc.-their resultant in each case is of such character as to insure relative stability of composition, density, and localization of the given group of species. As they combine, larger units of supramolecular, submicroscopic, and finally, of microscopic order arise, each durable or "viable" only in a particular typical constellation of conditions."

Species within a system interact to form larger systems. Systems on a cellular level form tissues, which form organs, then organisms, populations, and eventually ecosystems, each durable or "viable" only in a particular typical functional relational set of conditions. Levels of mechanistic complexity emerge through atomistic interaction.

6. Organization in space and content of the system and its constituents set the frame for later settlement of different members of species, giving existential and operational prerequisites of new members of the system. Organization is based on all surfaces and interfaces of constituents of a system. External aspects of species of a system and their interaction define function of the system, and exclusion or inclusion of new species to the mechanism of the system.

7. A given boundary/surface ${ }^{62}$ of a system will favor integration of particular species that will concentrate that area and crowd out other species not equally fit to that

\footnotetext{
${ }^{60}$ Coacervation- a tiny spherical droplet of assorted organic molecules which is held together by hydrophobic forces from a surrounding liquid. (Freeman, p. G:6)

61 (Weiss, p. 253)

${ }^{62}$ Not necessarily boundary or surface of the entire system but the boundary or surface of the constituents of the system or of the entire system.
} 
system. Surfaces of the mechanistic species favor integration of species that fit within physical chemical and spatial organization already present.

8. Surface species of a system have a unique role in determining events within its interior; "They assume the functional properties of membranes" ${ }^{3}$. Species control and select transfer of substances between systems they divide. Through aggregation of mechanistic components function rises out of the system.

9. Boundary/surface species will become fixed into an interface, and force a definite orientation relative to that interface below its surface. This will form an orderly array to which layers within the interior can become fixed. A stacking up process is initiated through which organization can be gradually extended into the interior, creating an increasing diversity of conditions as it proceeds. Function of the system emerges through organization from the external stable appearance, to internal interplay of mechanisms.

10. If conditions change along the boundary/surface so that they are no longer compatible with existential and operational prerequisites of the boundary/ surface species, a new assortment of species better fitted to the situation will take position as the interface that will set new organization for the interior, leading to an alternate fate of the system. When enough pressure is applied to a system, a watch for example, the systems environmental conditions change no longer fulfilling existential and operational conditions. In this system parts of the watch once disengaged would regroup with other mechanisms to form other systems; possibly aggregate with other mechanisms to form more watches, or to become mechanisms within a radio.

${ }^{63}$ (Weiss, p. 254) 
While the ten points formulated attempt to provide a non-anthropomorphic based description of phenomena, describing interaction in a mechanistic and atomistic way, leads to the system being directed from outside. The boundary determines membership into the system. Placing emphasis entirely on mechanical aspects of life; leads to the need to assert a central directing agency dependent on the form of life, not function. The pendulum of science again shifted to an atomistic mechanistic view of life with introduction of specificity to the scientific lexicon. "Thus with the start of the nineteenth century, a new science was to appear. Its aim was no longer to classify organisms, but to study the processes of life; its object of investigation was no longer the visible structure, but organization." ${ }^{14}$ Discourse of organization was to discover "life's grand design." ${ }^{\prime 5}$ With organization being object of study, specificity was an important tool in understanding organization. Problems and experiments of the 1930s and 1940s were framed in discourse of functional specificities. ${ }^{66}$ "Specificities dictated and governed successive cycles of life." Specificity of structures interacting to form organized biological organisms was the space for scientific advancement and understanding.

"Experimental studies showed that genes were highly specific with respect to gene products; enzymes exhibited a high degree of specificity for their substrates; the binding of antigen and antibody became an index of specificity in immunology and related fields; bacteria and viruses where often characterized with respect to their host-range

\footnotetext{
${ }^{64}$ (Kay, p. 41)

${ }^{65}$ (Kay, p. 41)

${ }^{66}$ (Kay, p. 42)

${ }^{67}$ Jacques Loeb, "The Organism as a Whole," p 61, 1916 as cited in (Kay, p. 44)
} 
specificities; taxonomies of species were established based on experimentally measured serological ${ }^{68}$ differences." 69

Proteins became focus of biological investigation, as imperative players in organization of complex organisms. The question of how biological specificity was transmitted across generations focused on proteins as bearer of specificity. "Of all the macro- and microelements conjoined in the organization of perpetuation of the body, proteins came first, privileged as the ontological substance of life. As the material representatives of heredity, at least until the early 1950s, they bore biological and chemical specificity."70 Previous to discoveries of DNA as the selfreplicating molecule, proteins were thought to hold secrets of organizational specificity, thus secrets of life. "Across the life sciences, the lock-and-key metaphor served as an exchange medium, a conceptual and experimental bridge, which related form to function along the material continuum of biological specificity, from species to molecule."71

While language of specificity had mechanistic conceptual backing, it did not provide an explanation for biological processes, just abstracted conceptualization of the processes. "In many instances the term specificity possessed more of a metaphorical quality and heuristic value than operational force. Unless detailed through some kind of concrete structure, measure, mechanism, and experimental procedure, specificity was not really an explanation (explanan) but that which needed

\footnotetext{
${ }^{68}$ Study of plasma serum and other bodily fluids.

${ }^{69}$ (Kay, p. 42)

${ }^{70}$ (kay, p. 48)

${ }^{71}$ (kay, p. 43)
} 
explaining (explnandum)." ${ }^{, 2}$ Specificity may have required an explanation, but there was an agreed upon physical description of the lock and key which provided it with conceptual backing.

Metaphoric language is necessary for formation of conceptual problems. Language to describe a problem cannot be seen also as its answer. "The main objection to symbolic expressions of this kind comes from the fact that instead of formulating the problems, they merely label them. We may not be able to dispense with such descriptive terms for some time to come, but we must guard against giving them any explanatory value."73 Mysteries of life and experience are not locks and keys but appearance of biological components complimentary interaction can be conceptualized in a way that resembles a lock and key. Describing interactions of life through a mechanistic view of specificity, leads to the assumption that function of a system naturally arise from the atomic parts. This leaves an emphasis on a directing force external to the parts. A description is given of the system, but there is still a nonmaterial entity directing assemblage of the system from outside, as opposed to nonmaterial information internal to the system.

\section{Developmental Systems Theory; A Structured View of Life}

In 1986, Arbib and Hesse asserted, "Scientific revolutions are, in fact, metaphoric revolutions, and theoretical explanations should be seen as metaphoric redescription of the domain and phenomena." ${ }^{\prime 74}$ An attempt to understand complex biological systems has continually lead to conceptual bifurcation, asserting two

\footnotetext{
${ }^{72}$ Rosenbleuth, Arturu, Norbert Wiener, and Julian Bigelow; "Behavior, Purpose, and Teleology," 1943 as cited in (Kay, pp. 45-46)

${ }_{73}^{73}$ (Weiss, p. 239)

${ }^{74}$ Arbib and Hesse "The Construction of Reality," 1986; as cited in (Kay, p. 22)
} 
separate streams directing the organism, discussed earlier as vitalism or mechanism, function or form, information or specificity. A description is needed to capture both mechanistic and vitalistic nature of biological phenomenon. Susan Oyama has lead the call from developmental system theorists (DST) to eliminate dichotomous views in biology. DST is; "a general theoretical perspective on development, heredity and evolution. It is intended to facilitate the study of interactions between the many factors that influence development without reviving 'dichotomous' debates over nature or nurture, gene or environment, biology or culture."75

Advocates of DST believe the organism and the environment it is a part of have equal influence on development. The object of investigation should be the "developmental system," the organism rooted within developmental context of the environment. ${ }^{76}$ Concepts and terminology used to describe theories concerning life and heritability have evolved through history, and are described through either mechanistic or vitalistic metaphors that are culturally relevant for the time. Proponents of DST would like to eliminate conceptual dichotomies in science and society as a whole. The first step to eliminate dichotomous ideas, is a recognition of the continued presence and varying incarnations of dichotomies. Webster and Goodwin discuss a structuralist approach to description and theorizing concerning organisms, which possibly could be in line with stated goals of DST to eliminate this conceptual discrepancy.

\footnotetext{
${ }^{75}$ (Griffiths \& Gray, p. 417)

${ }^{76}$ (Griffiths \& Gray, p. 422)
} 
"Structuralism is concerned with order, its generation and transformation it rejects both atomism and holism."77 This does not entail that structuralist approach to organismal life rejects epistemic contributions of science. It does entail a differing conceptualization of organismal domain and life. Forms and functions of life deserve equal weight in theoretical description, as they are inseparable aspects of the same whole. Science cannot continue beating the dead horse of nature and nurture, genes and environment, mechanism and vitalism. All of these concepts are two sides of the same coin, life, they cannot be separated. When an attempt to separate or place primacy of action on one of these aspects, it leads to a conceptual disconnect, which results in an impediment to epistemic practices.

There are three aspects to the structuralist formulation of organismal life. First wholeness; "Structures are wholes, firstly, in the sense that they have the property of maintain themselves in being while their elements change, hence they are not reducible to the sum of their elements."78 This conceptualization of organisms as structures, thus wholes, gives weight to the physical forms present. Allowing for the incorporation of new members while old members of the structure degrade, but still the wholeness of the structure is maintained. The function is that of being a whole and this function is realized through the dynamic interchange of parts internal and external to the structure.

The second aspect of organismal life from a structuralist perspective is related to transformations. "Because structures obey laws there is a restriction on the 'coherent' forms which are possible; that is the potential set of transformations is a

\footnotetext{
${ }_{77}^{77}$ (Webster \& Goodwin, p. 40)

${ }^{78}$ (Webster \& Goodwin, p. 40)
} 
logically closed set, though not necessarily finite...individual organisms can undergo specific transformations as a consequence of internal or external perturbation."79 There is an emphasis on restrictions of coherent form, which allows for organisms to transform in a law governed way dependent on the set of possibilities provided by the physiochemical constitution of both the organism and the environment at a given time. This aspect formulates a conception of life attempting to not emphasize external or internal directing, dictating primacy over a given life form. This aspect of the organism and life as structure allows for both the mechanistic and vitalistic experience of life to be accounted for.

The third aspect of organisms as structures is self-regulation. This refers to; "The power of a structure to maintain a given member of the set of transformations in the face of perturbation. ${ }^{80}$ By making reference to power it implies a function, but there is also a mention to the member, or form, in which the function is actualized. This allows for a change in physical composition and orientation of parts of an organism while maintaining its individual status. "Small continuous changes in parameters can result in either small, continuous changes of form, or in large, discontinuous alterations..." ${ }^{81}$ A caterpillar undergoes metamorphosis to a butterfly; there is a set of structured transformations of the physical entity in which the function of its parts alter, but still the same organism persists.

These three conceptualizations of aspects of structure, or organismic life, does not imply a privileged role over the ever changing physical specificity of the

\footnotetext{
${ }^{79}$ (Webster \& Goodwin, p. 41)

${ }^{80}$ (Webster \& Goodwin, p. 41)

${ }^{81}$ (Webster \& Goodwin, p. 45)
} 
environment that which nurtures the organism, or the genetic nature of information which is an internal function of the physical forms of the organism. "Such a conceptualization is, of course, compatible with a variety of theories and does not necessitate any one particular theory. $" 82$ This formulation of organism as structure can fit with any of the previous formulations of life as mechanistic form or vitalistic function. It does not exclude old theories, but explicates their shortcomings, not allowing for a view of form or function to be accentuated. The structural conception of organisms is inherently interactional. It allows for transformation with the appearance of constancy.

The structuralist approach to organisms rejects both atomism and holism, vitalism and mechanism; as chosen metaphor for life. That is not to say that vitalist and mechanistic metaphors are wrong and in need of elimination, they are in need of integration. "Although exclusively atomistic conceptions of the organisms are untenable, that does not mean that atomistic association plays no role in biological phenomena: it takes its place in a larger scheme as a limiting case in which the set of potential forms has only one member. This larger scheme is a structuralist conception of the organism." 83 This can be construed as, the atomistic perspective is the static synchronic state of components of a system. Mapping specific orientation of chemical components, reducing the whole to its parts and orientation. The limiting case is the diachronic history, or level of order, which gives rise to the synchronic. The progression of mechanistic interaction over time dictated by physiochemical interaction gives rise to the whole, or vitalistic aspect of life dependent on the

\footnotetext{
${ }^{82}$ (Webster \& Goodwin, p. 41)

${ }^{83}$ (Webster \& Goodwin, p. 38)
} 
previous state of the system. The atomic structure gives the space for function to rise in time through minute physiochemical changes to a system.

In a given environmental space there is a set of physical members of an extant system. All have specific chemical compositions and physical affinities. Within any given system due to both internal and external composition, governing laws limit actualization possible due to physiochemical relations in a particular time and place, dependent on the previous state of the system. There is not a preexisting essence that is in need of actualization, just physiochemical processes dependent on chance circumstances of the environment. Organismal development is a conditional process based on organization in physical three dimensional space progressing through time dictated by regularities of affinity based on physiochemical laws. Its members are that of already existing dynamic matter entering and exiting the system, changing and transforming due to formation and degradation from external and internal influences.

A twist on the myth of the Ship of Theseus ${ }^{84}$ allows for illustration of how mechanistic and vitalistic perspectives can be married to produce a better understanding of development and evolution of life. This holds a place for specificity and information as equally important in the descriptive process. In 'The logic of metabolism and its fuzzy consequences' Danchin and Sekowska use the myth of the Ship of Theseus to illustrate "the border between permanence and change" that is key to metabolic processes as well as life. An explication of the physical process of

\footnotetext{
84 "The ship wherein Theseus and the youth of Athens returned had thirty oars, and was preserved by the Athenians down even to the time of Demetrius Phalereus, for they took away the old planks as they decayed, putting in new and stronger timber in their place, insomuch that this ship became a standing example among the philosophers, for the logical question of things that grow; one side holding that the ship remained the same, and the other contending that it was not the same." Myth originally from Plutarch, 75 ACE; translated by John Dryden, 1994; as cited in (Danchin \& Sekowska, p. 19)
} 
altering a ship may help garner an understanding of how information and specificity can be integrated for a more comprehensive conceptualization of complex dynamic processes in which life presents itself.

This is an explanation concerning persistence and transitions of life, not formation of life in the universe. It will be accepted life is the product of a complex evolutionary past that cannot be definitively known, which occurred through purely physical processes. A twist on the myth of the ship of Theseus will illustrate how perturbation to a system over time may change the physical form while maintaining coherence and continuity of a system; how specificity and information can integrate to dictate stability of a system while its physical constitution changes. The order within the ship is akin to information, defined by Wiener as negative entropy. The components forming the order can be correlated to specificity as outlined by Weiss. With the interaction of the vitalistic and the mechanistic a more coherent conception of life can occur.

The ship in this illustration is dry docked but cared for in a similar manner as Theseus' ship, and can be paralleled to a caterpillar. Reconstruction of the ship is its processes of life. As planks of the ship decay and are removed, pitch from within these planks are collected to be used as resin, to caulk addition of new planks. This can be correlated with metabolic processes where macromolecules are cleaved, and the resultant products are appropriated into other parts of the system. A new plank is added for each removed. This is akin to the appropriation of nutrition by the caterpillar, to sustain the processes of life the physical components must be added. The waste of the ship is used for fertilizer, the nutrients of which help an orchard to 
grow that will be used as timber. All life produces waste that enriches the environment and other life forms. If those rebuilding the ship found because of a shift in the climate while altering the hull, it was needed to build walls to the ground, changing form to a barn. Organization is shifted, but maintains the same level of quantifiable order, information. Caterpillar becomes a chrysalis. Time passes and planks are continually added and rot. Those salvaging the ship are put under pressure by invaders and the shape of the barn slowly transforms into a church. A butterfly is produced. Again the level of order is maintained within the system while its physical manifestation changes over time, due to specific physical pressures and availability of resources. While the structure is being restored, it lives. A fire strikes the orchard, and no trees remain to form planks. The boat can no longer be restored its parts decay, becoming incorporated by other ordered systems. The butterfly dies, and enriches the environment.

Within this description there is allowance for order, transformation, and generation. Despite alteration of its physical components an aspect of the ship maintained the same; "The mysterious attribute lies in the information carried by the relationships that link the planks together." ${ }^{85}$ This statement seems inherently vitalistic. When taken with understanding information in this sense can be equated with negative entropy in the mathematical theory of communication as quantifiable order of a system, which is driven by mechanistic physiochemical interactions of specificity as outlined by Weiss. The level of order or information persists while the atomistic parts change through time. No physical entity is static, all life is a process

${ }^{85}$ Emphasis present in original text (Danchin \& Sekowska, p. 19) 
of breaking down and building organized structure driven by time and chemical affinity. "In a way, not so different form the build up of man-made crafts such as Theseus' boat, atoms are combined into all the components of life, following certain informational rules. Obeying these rules, however cannot be strictly accurate. They have a fuzzy character associated to the inevitable thermal fluctuations. $\$ 86$

Taking the view of organism as structure, giving equal weight to both the vitalistic nature of genetic information and mechanistic nurture of physiochemical specificity, may lay the ground for a new description of life and its processes; such as that of the developmental system, or co-constructing lock and key as object of inquiry based on cycles of contingency dictated by purely physical processes. This formulation of organismal life, if adopted into the system of science may produce questions, thus epistemic goals that do not rely on dichotomous distinctions. With a new metaphor that does not imply primacy of vitalism or mechanism, a greater understanding of organisms and life could be conceptualized by science and thus society. We may finally be able to bury the horse.

\section{Works Cited}

Canguilhem, G. (1963). The Role of Analogies and Models in Biological Discovery. In A. Crombie (Ed.), Scientific Change Historical studies in the intellectual, social and technical conditions for scientific discovery and technical invention, from antiquity to present: Symposium on the hitory of science University of Oxford 9-15 July 1961 (pp. 507-520). New York: Basic Books Inc.

Danchin, A., \& Sekowska, A. (2014, January). The logic of metabolism and its fuzzy consequences. Environmental Microbiology, 16(1), 19-28.

\footnotetext{
${ }^{86}$ (Danchin \& Sekowska, p. 21)
} 
De Klerk, G. J. (1979). Mechanism and Vitalism. A History of the Controversy. Acta Biotheoretica, 1-10.

Fowler, H., \& Fowler, F. (1934). The Concise Oxford Dictionary of Curent English. London: Oxford at the Clarendon Press.

Freeman, S. (2011). Biological Science Fourth Edition. San Fransisco: Pearson Education.

Godfrey-Smith, P. (2000, March). On the Theoretical Role of "Genetic Coding". Philosophy of Science, pp. 26-44.

Griffiths, P. E., \& Gray, R. (2005). Discussion: Three ways to misunderstand developmental systems theory. Biology and Philosophy, 417-425.

Jacob, F. (1973). The Logic of Life: A History of Heredity. Paris: Random House.

Johnson, G., \& Losos, J. (2010). The Living World Sixth Edition. New York: McGraw-Hill.

Kay, L. (2000). Who Wrote The Book of Life? A History of the Genetic Code. Stanford: Stanford University Press.

Lewontin, R. (1991). Biology as Ideology: The Doctrine of DNA. New York: HarperCollins.

Moitra, K. (2014). A Journey Through Genetics [Part I]. Washington D.C.: Biota Publishing.

Oyama, S. (1985). The Ontogeny of Information. Cambridge: Cambridge University Press.

Sterelny, K., \& Griffiths, P. E. (1999). Sex and Death: An Introduction to Philosophy of Biology. Chicago: University of Chicago Press.

Webster, G., \& Goodwin, B. (1982). The Origin of Species; a stucturalist approach. Journal of social and biological structures, 15-47.

Weiss, P. (1945). The Problem of Specificity in Growth and Development. Yale Journal of Biology and Medicine, 19(3), 235-280.

\footnotetext{
'Molecular Ecology

To speak symbolically of "affinities," is merely to outline the problem, not to attack it. It remains to resolve the described bio- logical phenomena into known phenomena of physical and chemical order. How such resolution could be envisaged will be indicated in the following. It will be essentially an elaboration of an earlier similar attempt to interpret cellular affinities in terms of molecular structure and organization.
} 
By way of preparation, it seems appropriate to transcribe the symbolic concepts of "cell" and "protoplasm" into terms of molecular phenomena. This transcription has a purely pragmatic purpose, namely, to create a more workable model of the cell. Its utility will soon become evident. It has led me to introduce a concept of the cell which can best be characterized as "Molecular Ecology." That is, a cell is to be viewed as an organized mixed population of molecules and molecular groups of the following properties and behavior.

(1) Each population is made up of molecular species of very different composition, sizes, densities, rank, and stability, from trivial inorganic compounds to the huge and highly organized protein systems. Some segments of these populations occur in relatively constant "symbiotic" groupings, often of a limited size range; these form the various particulates of the cell content.

(2) It is one of the fundamental characteristics of cellular organization that the various species constituting the population are not self-sufficient, but depend in various degrees upon other members of the population as well as upon the physical conditions prevailing in the space they occupy. Survival and orderly function of the total population are predicated on the presence of all essential members in definite concentrations, combinations, and distributions.

(3) In view of this intricate interdependence, given molecular species can exist and given interactions between species can occur only within a certain limited range of conditions specific for each kind. We might call these conditions the "existential and operational pre- requisites" for each molecular species or group. The probability of members of a given species to persist, hence to be found, in any but the appropriate setting, would be extremely low.

(4) If the specific existential and operational prerequisites for the various molecular species and groups differ at different sites of the cell, different species will automatically become segregated into their appropriate ecological environments. As a result, even a wholly indiscriminate mixture can become sorted out into a definite space pattern. Certain species will assemble in relatively stable combinations, like biotic groups, while others, mutually incompatible, will separate.*

(5) While the conditions and forces which determine the molecular regrouping are of the most diverse sortselectric charges, surface tensions, coacervation, solubility, chemical affinities, adsorption, enzyme-substrate relations, mobility, elasticity, etc.-their resultant in each case is of such character as to insure relative stability of composition, density, and localization of the given group of species. As they combine, larger units of supramolecular, submicroscopic, and finally, of microscopic order arise, each durable or "viable" only in a particular typical constellation of conditions.

(6) Organization in space of the content of the cell, and of any of its constituent particulate elements as well, therefore, presupposes a primordial system of spatially organized "conditions" to set the frame for the later differential settlement of different members of the dispersed molecular populations. Such conditions can presumably only exist in systems with stability like solids. Systems answering this demand are presented by all surfaces and interfaces in the cell, which include the interfaces between one cell and another, between cell and medium, nucleus and cytoplasm, nudeolus and nuclear sap, chromosomes and nuclear matrix, chromatic and achromatic substance, as well as between all other formed cell components and the interstitial fluid.

(7) A given surface area of given constitution will therefore favor the adsorption of a given assortment of molecular species, which will thus concentrate in that area and thereby crowd out other species not equally fit to occupy that particular zone. In this manner, the various surfaces will gradually become settled by mosaics of "frontier populations" recruited from the subjacent territories. ${ }^{* *}$

(8) Owing to their frontier position, these surface populations acquire a unique role in determining the subsequent course of events in the interior. Without necessarily being morphologically distinct, they assume the functional properties of membranes. That is, they control the selective transfer of substances and energy between the molecular realms they divide.

(9) Polar molecules (e. g., the biologically prominent lipoproteins), in becoming fixed to an interface, are forced into a definite orientation relative to that interface, and hence, relative to one another. This orderly array makes it possible for the resulting polarized layer to serve now, in its turn, as a new surface along which further molecular layers from the interior can become fixed, with the selection depending on the physical and chemical properties of the free ends of the righted molecules of the first layer. Thus, a stacking up process is initiated through which 
organization can be gradually extended into the interior, creating an increasing diversity of conditions as it proceeds.

(10) If the conditions along an interface change in such a manner that the new conditions are no longer compatible with the continued existence of the old frontier population, the latter will be crowded out by a new assortment of species better fitted to the new situation. As this new frontier population settles in the controlling master position, it sets a new master pattern for the events in the interior, causing the further fate of the cell to take a radically different turn. Different contact surfaces can thus entail qualitative changes in the cell by bringing different segments of the molecular population into the controlling surface positions. The concept formulated in these ten points takes into account the growing realization that the structural and working order of the cell is based not on the presence of a fixed mechanical framework pervading it-abundantly disproved by the facts-but on a regular distribution in space of the various intracellular processes: a dynamic rather -than static skeleton, maintained by metabolic energy and determined in its characteristics by some definite geometrical order in the field of its operation. This order we conclude to be an order of "conditions," going back in last analysis to the typical organization of surfaces-"organization" in this sense referring to the particular non-random distribution of physical and chemical properties (see later). Pending evidence to the contrary, it is also possible to view the organization of genes as residing in their surface properties. In other words, the organization pattern of many, and perhaps all, living systems can be derived from a two-dimensional ground plan to which the third dimension is secondarily added by the selective stacking-up of various polar compounds in consecutive layers.

*We are omitting here from consideration the fact that many large organic molecules, such as the native proteins, seem to undergo constant metabolic renovation, exchanging constituents with their environment, but preserving their identity.' In terms of our analogy, this is the counterpart of the turnover of cells within the individual members of an animal population.

** Again for the sake of simplicity, we are ignoring here the fact that specific local conditions favor not only the adsorption of certain existing molecular species, but synthesis of new species as well. This point will be more fully discussed in a later section. 